\title{
Clinical efficacy of percutaneous vertebroplasty combined with intensity-modulated radiotherapy for spinal metastases in patients with NSCLC
}

This article was published in the following Dove Press journal:

OncoTargets and Therapy

19 August 2015

Number of times this article has been viewed

Yi Li ${ }^{1,2}$
Yi Qing

Zhimin Zhang ${ }^{3}$

Mengxia $\mathrm{Li}^{\prime}$

Jiaying $\mathrm{Xie}^{\prime}$

Ge Wang'

Dong Wang'

'Department of Cancer Center, Research Institute of Surgery, Daping Hospital, Third Military Medical University, ${ }^{2}$ Department of Oncology, Beibei Traditional Chinese Medical Hospital, Chongqing, ${ }^{3}$ Department of Oncology, Wuhan General Hospital of Guangzhou Command, People's Liberation Army, Wuhan, Hubei,

People's Republic of China
Correspondence: Dong Wang Department of Cancer Center, Research Institute of Surgery, Daping Hospital, Third Military Medical University, 10 Changjiangzhilu Road, Chongqing 400042, People's Republic of China

Tel +862368757151

Fax +862368894062

Email dongwang64@hotmail.com
Objective: This study aimed to evaluate the safety and efficacy of percutaneous vertebroplasty (PVP) combined with intensity-modulated radiotherapy (IMRT) for metastatic lesions of patients with non-small-cell lung cancer (NSCLC) at centrum vertebrae.

Methods: A total of 39 patients with spinal metastatic NSCLC (stage IV) were treated with PVP followed by IMRT (30 Gy/10F/2 W) for metastatic lesion at centrum vertebrae under local anesthesia. Retrospective analysis was done with medical records and radiological data. The change of visual analog scale (VAS), activities of daily living, and kyphotic angle was measured preoperatively. The presence of complications was assessed preoperatively (baseline) at 24 hours, 1 week, and 1, 3, 6, 12, and 24 months postoperatively, or until the patient died or was lost to follow-up. Survival was assessed in the group.

Results: A total of 39 consecutive patients were successfully treated with PVP via a translateral approach and IMRT. Their mean VAS score decreased from $7.93 \pm 1.09$ preoperatively to $4.14 \pm 1.15$ by the 24 -hour postoperative time point and was $3.92 \pm 1.23$ at 1 week, $4.27 \pm 1.93$ at 1 month, $3.24 \pm 1.35$ at 3 months, $2.27 \pm 0.96$ at 6 months, and $2.59 \pm 1.55$ at 12 months after the procedure. The mean VAS score at all of the postoperative time points was decreased significantly from the preoperative baseline score $(P<0.05)$. Activities of daily living evaluation showed that the patients had a significantly high life quality after the combined approach $(50.9 \pm 11.7 \mathrm{vs}$ $82.3 \pm 9.9, P<0.05)$. No severe complications were observed. Mild complications included two cases $(5.13 \%)$ of asymptomatic cement leakage into the epidural space and one case $(2.56 \%)$ of paravertebral leakage. Median survival time was extended to 13 months.

Conclusion: The safety and efficacy of PVP combined with IMRT in patients with NSCLC with metastatic lesions at centrum vertebrae and the ability to prevent the diseased vertebrae from further deformation and tumor infiltration into the vertebral body were demonstrated. PVP combined with IMRT should be the optimal technique for treatment of vertebral compression pain resulting from spinal metastatic NSCLC.

Keywords: percutaneous vertebroplasty, IMRT, NSCLC, spinal metastases

\section{Introduction}

Patients of non-small-cell lung cancer (NSCLC) with metastatic lesions are often in advanced stages of the disease at the time of diagnosis. Approximately $10 \%$ of cancer patients will present with symptoms related to vertebral metastases, and of these $40 \%-70 \%$ will have multiple vertebral levels involved. ${ }^{1}$ The treatment purpose is, therefore, to palliate pain and prevent complications by reducing the length of hospital stay and by improving performance status. Standard treatments include systemic therapies, such as hormonal therapy, analgesics and bisphosphonates, and local, focused on the lesion, such as radiotherapy (RT) and surgery. ${ }^{2}$ RT has been used for spinal hemangiomas 
since 1930. The principal goal of RT is remineralization of osteolytic bone. Intensity-modulated radiotherapy (IMRT) is a therapeutic strategy, but up to $20 \%-30 \%$ of patients do not respond to treatment, with no further treatment eventuality. ${ }^{3}$ IMRT provides local tumor control, significant pain relief, especially for multifocal lesions, but limited spinal stabilization. However, in cases of spinal pathologic compression fractures, immediate spinal stabilization is required. Vertebroplasty (VP) with polymethyl methacrylate (PMMA) was first introduced as a technique for the treatment of vertebral hemangiomas in $1987 .{ }^{4-6}$ Since that time, it has become a valuable therapeutic option in the management of axial back pain caused by osteoporotic fractures, metastasis, and multiple myeloma. ${ }^{7}$ Percutaneous vertebroplasty (PVP) can also be performed as a complement to RT to provide immediate vertebral stabilization. Also, it is a minimally invasive percutaneous procedure that is performed with the patient under light sedation and local anesthesia.

Only a few studies report on the long-term outcome of PVP combined with IMRT in the treatment of metastatic lesions of the spine. ${ }^{8-10}$ In this study, we evaluated the feasibility, efficacy, safety, and clinical pathways of PVP combined with IMRT for the treatment of osteolytic metastasis and compression fractures at centrum vertebrae in patients with NSCLC.

\section{Patients, materials, and methods Ethics}

The study protocol was in accordance with the ethical guidelines of the 1995 Declaration of Helsinki and was approved by independent ethics committees at Daping Hospital, Third Military Medical University (Chongqing, People's Republic of China). Written informed consent was obtained from the patients for the publication of this report and any accompanying images.

\section{Patient characteristics}

The retrospective study involved 39 patients with NSCLC with spinal metastatic who are medically unfit for surgery, have technically unresectable cancer, choose to be free from surgery, and are able to tolerate PVP and IMRT between September 2005 and June 2013 in our hospital. Following an explanation of therapeutic alternatives, treatment selection between PVP combined with IMRT or not was decided by the patient with the oncologists.

The mean age of the study participants was 56 years (range: 39-74 years). All patients underwent plain radiography and computed tomography (CT) scanning, while most of them underwent radionucleotide bone scanning and magnetic resonance imaging of the spine. The most commonly involved spine levels are between T10 and L5. Table 1 summarizes the characteristics of the patients in this study. The length of follow-up review was calculated from the date of procedure to the most recent clinic visit or death.

\section{Treatment procedure}

PVP was performed as mentioned elsewhere. ${ }^{11}$ Briefly, PVP was performed with a digital subtraction angiography unit with a C-arm (Angiostar, Siemens) in the neurointerventional angiography suite. Anatomic landmarks and structures differ according to the vertebral level. Depending on the site of the lesion in the thoracic and lumbar regions, four different approaches were possible: the transpedicular approach, with reliance on vertebral pedicles as landmarks; the posterolateral approach, which was initiated at a point. Unilateral transpedicular approach was used in most of patients. The metastatic area was sterilized, and local anesthesia of the skin and soft tissues was achieved by injecting $3 \mathrm{~mL}$ of $1 \%$ lidocaine. The needle tip was positioned as near to anterior margin of vertebral body as possible. The cement injection process was continuously monitored under fluoroscopic control in the lateral plane. Approximately $0.5 \mathrm{~mL}$ of prepared bone cement (approximately 20 g PMMA powder mixed with $10 \mathrm{~mL}$ monomer until suitable for injection) was then injected prior to scanning. Cement injection was terminated when the PMMA reached the posterior margin of the vertebral body. Immediately, a three-dimensional CT scan was then performed to determine the distribution of the cement after withdrawal of the needle and completion of the PVP (Figures 1 and 2). Antibiotics were administered 1 day before and for 2 days after the procedure.

The IMRT was performed in the vertebroplasted vertebras and others with osteolytic lesion after patients undergoing PVP for approximately 3 days using an $8 \mathrm{MV}$ linear (Precise Treatment System ${ }^{\mathrm{TM}}$; ELEKTA, Stockholm, Sweden) at a dose rate of $2 \mathrm{~Gy} / \mathrm{min}$ with standard fractionation. ${ }^{12}$ Before treatment, all plans underwent a quality assurance test that included a film isodose curve comparison and absolute dose check with an ion-chamber at the isocenter under a cylindrical water phantom designed in-house. IMRT plans were prepared using the Helio inverse planning system. The gross tumor volume (GTV) of a tumor was defined as the volume of gross visible tumor plus margins of approximately 2-4 mm. The clinical tumor volume (CTV) was defined as the GTV plus a margin. The planning target volume was defined as the CTV plus $3 \mathrm{~mm}$ margins. To minimize the field-to-field junction error, the upper and lower regions were irradiated using an anterior-posterior portal with the same isocenter as IMRT 
Table I Clinical characteristics of 39 patients with NSCLC with spinal metastasis

\begin{tabular}{|c|c|c|c|c|c|c|}
\hline Case number & Age (years) & Sex & Pathology & Centrum for PVP & Centrum for RT & OS (months) \\
\hline $\mathrm{I}$ & 47 & $M$ & $A D$ & T7, 9, I2, LI.3 & C7 & 11 \\
\hline 2 & 73 & $M$ & $A D$ & TIO & TIO & 9 \\
\hline 3 & 61 & M & SCC & $\mathrm{T} 4,6,9$ & T3-11 & 14 \\
\hline 4 & 59 & $M$ & NSCLC & $\mathrm{T} 8,9$ & $\mathrm{~T} 8,9$ & 9 \\
\hline 5 & 46 & $\mathrm{~F}$ & NSCLC & TI, T7 & $\mathrm{TI}$ & 43 \\
\hline 6 & 58 & M & $A D$ & T7-12, LI & T7-LI & 45 \\
\hline 7 & 65 & $M$ & NSCLC & L4 & $\mathrm{L} 4$ & 39 \\
\hline 8 & 71 & M & NSCLC & $\mathrm{T} 8,10,12$ & T8-12 & 9 \\
\hline 9 & 39 & M & $A D$ & L3, 5 & $\mathrm{C} 3, \mathrm{~L} 3,5, \mathrm{SI}-3$ & 66 \\
\hline 10 & 66 & $M$ & $A D$ & L5 & TI2-S4 & 6 \\
\hline 11 & 65 & M & $A D$ & T9, LI & T3-11 & 5 \\
\hline 12 & 46 & $\mathrm{~F}$ & $A D$ & $\mathrm{T7}, 9$ & $\mathrm{T7}, 9$ & 16 \\
\hline 13 & 59 & $M$ & $A D$ & L3, 4, 5 & L2-5 & 6 \\
\hline 14 & 72 & M & NSCLC & $\mathrm{L} 2,5$ & T4-8, L2, 5 & 17 \\
\hline 15 & 52 & M & $A D$ & T9 & T9 & 13 \\
\hline 16 & 65 & $M$ & $A D$ & LI, 2 & C5, T2, LI, 2 5, SI & 15 \\
\hline 17 & 61 & M & $A D$ & L2, 3 & C4-7, T4-8, TI2-L5 & 15 \\
\hline 18 & 55 & M & SCC & L3-5 & L3-5 & 1 \\
\hline 19 & 71 & $M$ & $A D$ & $\mathrm{C} 4$ & C4, L4-5 & 14 \\
\hline 20 & 42 & M & SCC & TI2, LI & $\mathrm{TI} 2, \mathrm{LI}$ & 5 \\
\hline 21 & 52 & $M$ & $A D$ & TI2, LI-L5 & TI2-L5 & 3 \\
\hline 22 & 42 & $M$ & $A D$ & L2-3 & L2-3 & 64 \\
\hline 23 & 63 & M & $A D$ & $\mathrm{C} 4$ & C4-7 & 14 \\
\hline 24 & 56 & M & $A D$ & $\mathrm{~T} 2, \mathrm{~T} 5$ & TI-5, T9, TII, L5 & 15 \\
\hline 25 & 63 & M & $A D$ & T9 & T9 & 45 \\
\hline 26 & 74 & $\mathrm{~F}$ & SCC & $\mathrm{TI} 2, \mathrm{LI}$ & TII-S2 & 7 \\
\hline 27 & 68 & $\mathrm{~F}$ & NSCLC & L2-3 & L2-3 & 1 \\
\hline 28 & 65 & $\mathrm{~F}$ & NSCLC & LI, 2 & LI, 2 & 2 \\
\hline 29 & 69 & $\mathrm{~F}$ & NSCLC & $\mathrm{C} 4$ & $\mathrm{C} 4$ & 2 \\
\hline 30 & 65 & $\mathrm{~F}$ & $A D$ & T7-9, LI & T7-9, LI & 2 \\
\hline 31 & 62 & $M$ & NSCLC & $\mathrm{T} 4,6$ & $\mathrm{~T} 4,6$ & 3 \\
\hline 32 & 74 & $\mathrm{~F}$ & NSCLC & T7-12, LI & T7-12, LI & 3 \\
\hline 33 & 67 & $\mathrm{~F}$ & NSCLC & TI2, LI & TI2, LI & 3 \\
\hline 34 & 64 & M & SCC & $\mathrm{LI}-3$ & $\mathrm{LI}-3$ & 4 \\
\hline 35 & 52 & $M$ & NSCLC & L2-3 & L2-3 & 33 \\
\hline 36 & 58 & $F$ & NSCLC & $\mathrm{C} 4$ & $\mathrm{C} 4$ & 30 \\
\hline 37 & 63 & M & $A D$ & LI, 2 & LI, 2 & 29 \\
\hline 38 & 61 & $M$ & NSCLC & $\mathrm{C} 3$ & $\mathrm{C} 3$ & 28 \\
\hline 39 & 48 & $M$ & NSCLC & $\mathrm{C} 4$ & $\mathrm{C} 4$ & 19 \\
\hline
\end{tabular}

Abbreviations: AD, adenocarcinoma; F, female; M, male; NSCLC, non-small-cell lung cancer; OS, overall survival; PVP, percutaneous vertebroplasty; RT, radiotherapy; SCC, squamous cell carcinoma.
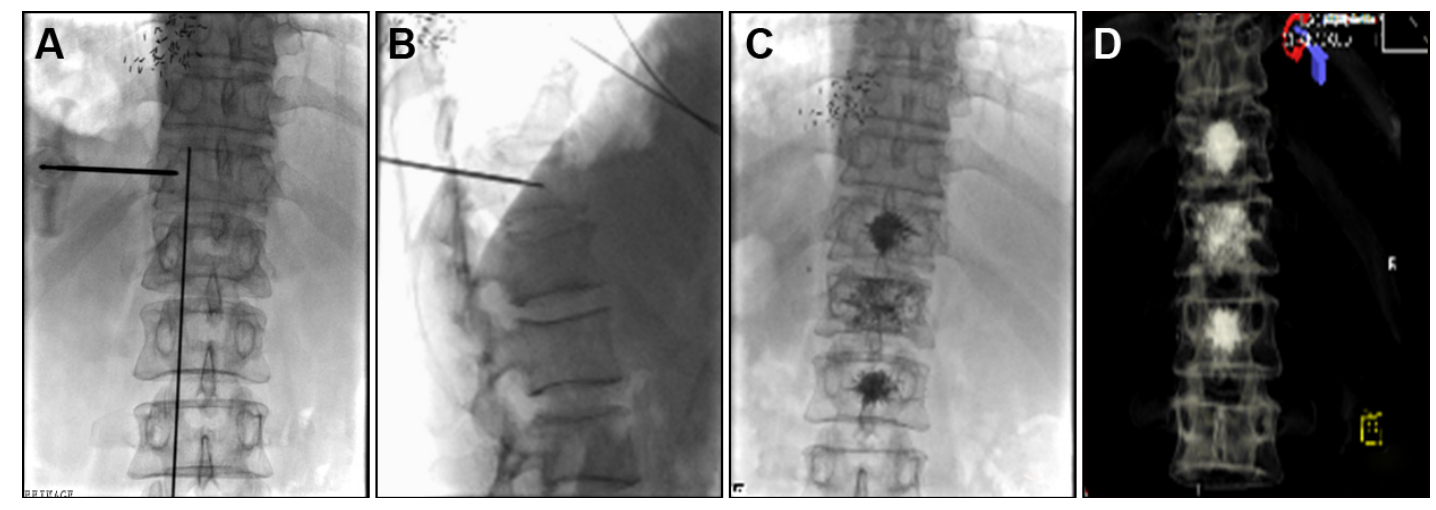

Figure I X-ray image scan and serial radiographs of PVP to TIO-TI2 in a patient with NSCLC with multifocal metastases.

Notes: (A) The location of metastasis before PVP. (B) The needle tip was positioned as near to anterior margin of vertebral body. (C) The PMMA reached the posterior margin of the vertebral body. (D) 3D computed tomography scan after withdrawal of the needle and completion of the PVP.

Abbreviations: NSCLC, non-small-cell lung cancer; PMMA, polymethyl methacrylate; PVP, percutaneous vertebroplasty. 

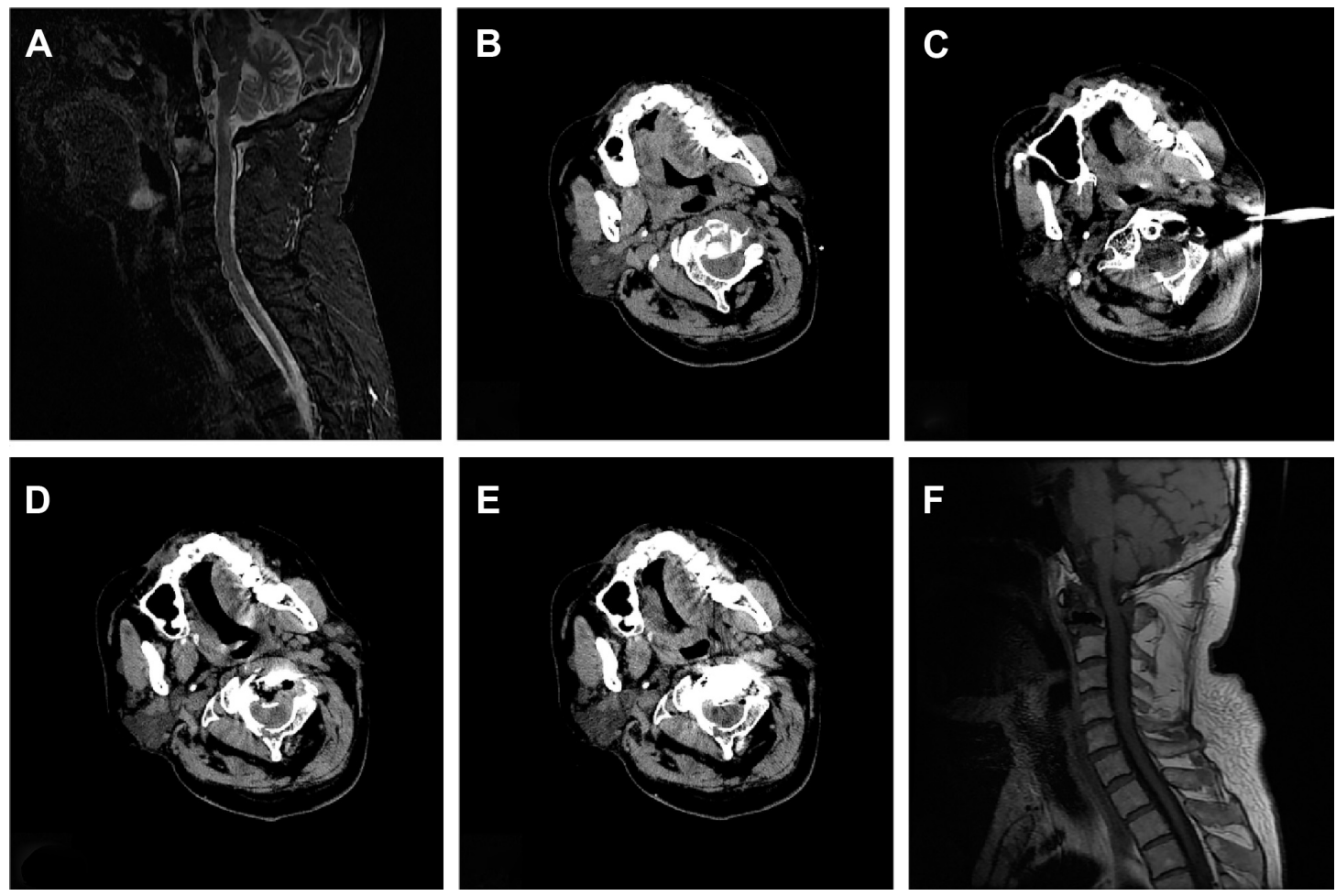

Figure 2 PVP using a CT-guided translateral approach via the space between the carotid sheath and vertebral artery in a patient with NSCLC with metastasis to C2.

Notes: (A) MRI demonstrates the osteolytic metastasis in C2 before PVP treatment. (B) The location of metastasis before PVP. (C) The needle tip was positioned as near as possible to anterior margin of vertebral body using CT-guided. translateral approach. (D) The tip is advanced toward the osteolytic portion of the targeted cervical spine. (E) The distribution of the cement after completion of the procedure. (F) MRI demonstrates the osteolytic metastasis in C2 has disappeared after 6 months with combined PVP and IMRT treatment.

Abbreviations: CT, computed tomography; IMRT, intensity-modulated radiotherapy; MRI, magnetic resonance imaging; NSCLC, non-small-cell lung cancer; PVP, percutaneous vertebroplasty.

treatment. To design an inverse plan with the potential to provide both physical and biologic benefits, we assigned different doses to different targets, similar to the concept of simultaneous integrated boost. The dose regimen was designed to keep the CTV receiving conventional fractionation but to accelerate the dose to the GTV. Initially, 30 Gy were administered to the metastatic area in 10 fractions over 2 weeks. The goal was to deliver a minimum dose of $30 \mathrm{~Gy}$ to the metastatic area.

\section{Assessment indices}

A visual analog scale (VAS), which was rated pain status of patients before and after the procedure, was performed according to standard procedures as previously described. ${ }^{9}$ VAS was classified as follows: a score of 0 indicated no pain and a score of 10 represented maximal pain. All enrolled patients were included in the intention-to-treat analysis of efficacy. The other assessment dates, including VAS, treatment response, mainly in terms of degree of pain et al were obtained by conducting clinical interviews in person, via telephone, or via mail at fixed intervals after their treatment sessions (at 1 week and 1, 3, 6, and 12 months) or until the patient died or was lost to follow-up. The analgesic efficacy of PVP was recorded, based on $50 \%$ or greater improvement in pain versus baseline.

The complications of the treatment, including severe complications (ie, tumor-related symptoms, pulmonary embolism, cardiogenic failure, septic shock, respiratory failure, or death) and mild complications (ie, infection, asymptomatic cement leakage) were recorded together with each patient's clinical information. The activities of daily living (ADL) scale is frequently used in clinical trials for tumor and assesses patient functional ability. Changes in ADL scales were observed for patients. The ADL scale is as follows: ${ }^{12}$ very effective - the decrease of ADL score was $\geq 6$ after treatment, effective - the decrease of ADL score was $\geq 3$ and smaller than 6 after treatment, and invalid - the increase of ADL score was $<3$.

\section{Statistical analysis}

Statistical analysis was performed with SPSS 13.0 (SPSS Inc., Chicago, IL, USA). Survival rates were calculated from the date of the initiation of treatment until death or the last follow-up for surviving patients using the Kaplan-Meier method. Values are given as mean \pm standard deviation. A $P$-value $<0.05$ was considered statistically significant. 


\section{Results}

Thirty-nine consecutive patients were successfully treated with PVP via a translateral approach combined with IMRT. All the PVP procedures were completed within 40 minutes to 1 hour. The numbers of patients available for VAS evaluation at each follow-up interval were $39(100 \%)$ at 24 hours and 1 week, $38(97.44 \%)$ at 1 month, $27(68.23 \%)$ at 3 months, $17(43.59 \%)$ at 6 months, and $6(15.38 \%)$ at 1 year. Their mean VAS score decreased from $7.93 \pm 1.09$ preoperatively to $4.14 \pm 1.15$ by the 24 -hour postoperative time point and was $3.92 \pm 1.23$ at 1 week, $4.27 \pm 1.93$ at 1 month, $3.24 \pm 1.35$ at 3 months, $2.27 \pm 0.96$ at 6 months, and $2.59 \pm 1.55$ at 12 months after the procedure. The mean VAS score at all of the postoperative time points differed significantly from the preoperative baseline score $(P<0.05$; Figure 3). ADL evaluation showed that the patients had a significantly high life quality after the operation for 6 months (50.9 \pm 11.7 vs $82.3 \pm 9.9, P<0.05$; Table 2$)$. No other severe complications were observed. Mild complications included two cases $(4.86 \%)$ of asymptomatic cement leakage into the epidural space and one case $(2.43 \%)$ of paravertebral leakage.

The length of follow-up review was calculated from the date of procedure to the most recent clinic visit or death. Median survival time was extended to 13 months in this group (Figure 4).

\section{Discussion}

Incidence of spine metastases is likely to increase as cancer patients live longer partly due to early detection and also because of improvements in medical care. Bone metastases are a frequent complication of cancer and bones are the third most common site for metastases following lung and liver. ${ }^{13}$ Of the various bones, the spine is the most common site of metastases. Within the spine, the incidence varies, thoracic $(68 \%-70 \%)$, lumbosacral $(16 \%-22 \%)$, and cervical $(8 \%-15 \%) .{ }^{14}$ The treatment of painful vertebral metastases is a major therapeutic challenge. $\mathrm{RT}$ is efficacious in palliating painful uncomplicated bone metastases, especially for multifocal lesions and can reduce analgesic requirements for these patients. The RT overall response rates were approximately $60 \% .^{15}$ Tumor inhibition of the release of chemical pain mediators is the main mechanism by which RT probably acts. However, RT does not correct spinal instability, and its efficacy is delayed. Unlike the delayed effects of RT, PVP provides immediate strengthening of the anterior column, which may limit painful vertebral body fracture.

Results of other studies of PVP: in metastatic spinal disease, for example, Lim et a $1^{16}$ performed PVP in 185 vertebral body of 102 patients, $81 \%$ patients with metastases, and 19\% with multiple myeloma. The reported mean follow-up period was 12.2 months. VAS score for back pain was 8.24 preoperatively, 3.59 at postoperative 1 day, 4.08 at postoperative 3 months, and 5.22 postoperative at 1 year; vertebral body compression ratio changed from $21.33 \%$ preoperatively to $13.82 \%$ (postoperative 1 day), $14.36 \%$ (3 months), and $16.04 \%$ (1 year). Cortet et $\mathrm{al}^{17}$ reported on the treatment of PVP in 37 patients, 29 with metastases, and eight with multiple myeloma. They found a decrease in pain within 48 hours of PVP in $97 \%$ of their 37 patients, complete pain relief in $13.5 \%$, significantly reduced pain in $55 \%$, and moderately reduced pain in $30 \%$. Beneficial effects were seen in $89 \%$ at 3 months and $75 \%$ after 6 months. Fourney et al ${ }^{18}$ have performed PVP and kyphoplasty in patients undergoing 65 vertebroplasties and 32 balloon kyphoplasties; pain was completely absent in $84 \%$ and no change in $9 \%$. The median

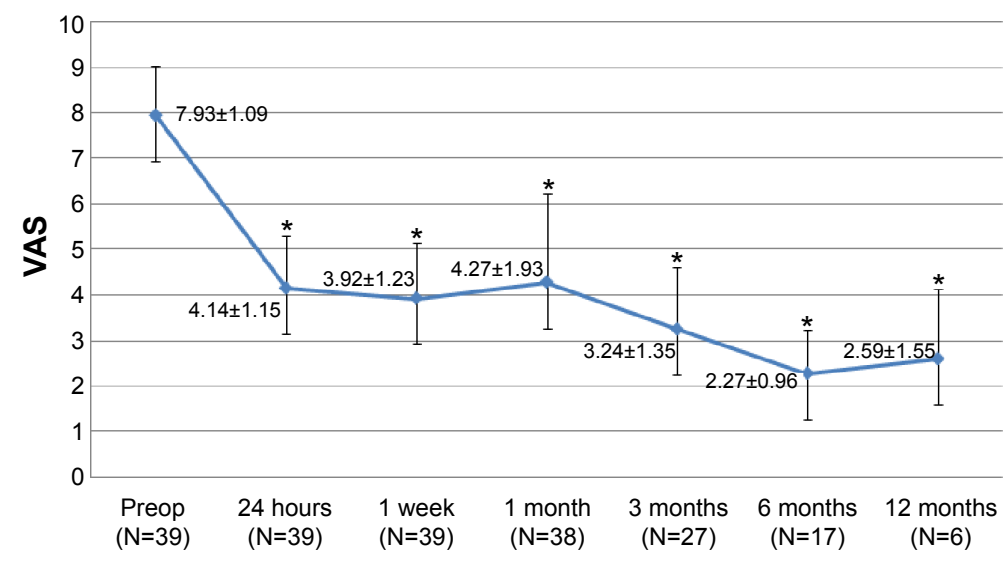

Figure 3 Visual analog scale (VAS) change of patients of at each pre- and postoperative follow-up time.

Notes: Data are expressed as mean \pm standard deviation. The differences between the VAS scores prior to VP and at I day, I week, and I, 3, 6, and I 2 months, respectively, are statistically significant $(P<0.05)$. $* P<0.05$ in comparison to preoperative.

Abbreviations: Preop, preoperative; VP, vertebroplasty; N, number of follow-up patients. 
Table 2 The ADL scores at 6 months pre- and postoperative of 39 patients with NSCLC with spinal metastatis (mean \pm SD)

\begin{tabular}{|c|c|c|c|}
\hline $\begin{array}{l}\text { Activity } \\
\text { (scale) }\end{array}$ & $\begin{array}{l}\text { Preoperative } \\
(\mathrm{N}=39)\end{array}$ & $\begin{array}{l}\text { Postoperative } \\
6 \text { months }(\mathrm{N}=17)\end{array}$ & $P$-value \\
\hline Eating & $7.7 \pm 1.7$ & $9.5 \pm 1.2$ & ns \\
\hline Bathing & $3.1 \pm 1.1$ & $3.3 \pm 1.1$ & ns \\
\hline Make-up & $3.2 \pm 0.8$ & $4.5 \pm 0.9$ & ns \\
\hline Dressing & $4.3 \pm 11.7$ & $6.7 \pm 1.9$ & ns \\
\hline $\begin{array}{l}\text { Stool } \\
\text { control }\end{array}$ & $6.9 \pm 10.5$ & $7.1 \pm 1.7$ & ns \\
\hline $\begin{array}{l}\text { Urination } \\
\text { control }\end{array}$ & $7.1 \pm 1.2$ & $9.3 \pm 1.5$ & ns \\
\hline $\begin{array}{l}\text { Walking } \\
(50 \mathrm{~m})\end{array}$ & $5.2 \pm 1.1$ & $11.2 \pm 0.6$ & $<0.05$ \\
\hline $\begin{array}{l}\text { Moving } \\
\text { a chair }\end{array}$ & $3.2 \pm 0.9$ & $9.3 \pm 11$ & $<0.05$ \\
\hline $\begin{array}{l}\text { Ascending } \\
\text { stairs }\end{array}$ & $2.5 \pm 0.7$ & $8.6 \pm 0.5$ & $<0.001$ \\
\hline $\begin{array}{l}\text { Descending } \\
\text { stairs }\end{array}$ & $2.1 \pm 0.4$ & $7.7 \pm 0.3$ & $<0.05$ \\
\hline Total & $50.9 \pm 11.7$ & $82.3 \pm 9.9$ & $<0.05$ \\
\hline
\end{tabular}

Abbreviations: ADL, activities of daily living; NSCLC, non-small-cell lung cancer; $\mathrm{ns}$, not significant; $\mathrm{N}$, number of patients.

pre- and postoperative VAS scores were 7.93 and 2, respectively $(P<0.001)$. Pain reduction remained significant at each follow-up interval through 1 year $(P=0.02)$. Furthermore, Pflugmacher et al ${ }^{19}$ reported on the treatment of 31 patients with 64 balloon kyphoplasty procedures in pathologic vertebral body fractures. The median pain scores (VAS) decreased significantly $(P<0.05)$ from pre- $(8.8)$ to posttreatment (3.1). Recently, Guo et al ${ }^{11}$ have reported 15 cervical vertebral body treated with CT-guided PVP via a translateral approach.

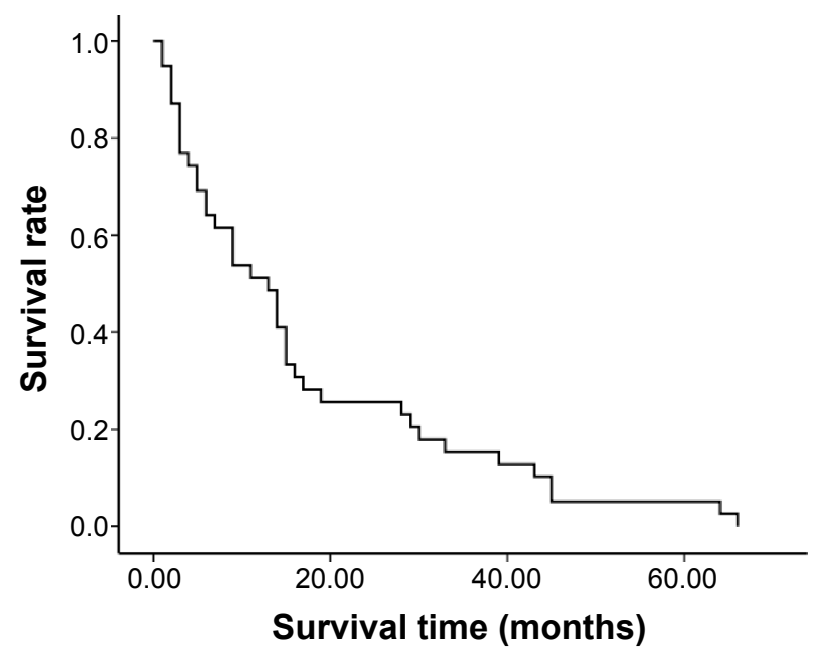

Figure 4 Overall survival curves of each treatment modality for patients with NSCLC.

Note: Median survival time was extended to 13 months in PVP combined with IMRT.

Abbreviations: IMRT, intensity-modulated radiotherapy; NSCLC, non-small-cell lung cancer; PVP, percutaneous vertebroplasty.
The mean VAS score at all of the postoperative time points differed significantly from the preoperative baseline score $(P<0.05)$. No severe complications were observed. These results are in concordance with our result, which demonstrated significant change of VAS after PVP.

The majority of studies have found a reduction in pain after VP, with the improvement in pain ranging from $20 \%$ to $79 \%$ at 1 month in the literature. ${ }^{18-21}$ In this study, we first performed the treatment of PVP combined with IMRT for vertebral metastases of patients with NSCLC and evaluated the safety and efficacy of the treatment for these patients. Pain relief remained in $97.44 \%$ of the cases (38 of 39) at 1 month follow-up and in $43.59 \%$ of the cases at 6 months.

From our results, we can see that the mean VAS score decreased significantly by the 24 -hour postoperative time point and was $2.59 \pm 1.55$ at 12 months after the procedure. ADL evaluation has also showed that the patients had a significantly high life quality after the operation for 6 months. No other severe complications were observed. Mild complications included two cases (5.13\%) of asymptomatic cement leakage into the epidural space and one case $(2.56 \%)$ of paravertebral leakage. All these results have showed that the treatment is safe and effective on these patients.

The VP was performed prior to radiation therapy in our study, which corroborates the opinion from Zhao et al. ${ }^{22}$ The reason for this regimen includes that 1) the analgesic effects of the former are immediate and spinal stability is addressed; 2) the radiation therapy can lead to hardening of the bone, making the VP more difficult to perform;;,23 and 3) the malignant tissue is compressed and relocated to subcortical areas in VP, which support local control by radiation therapy later. ${ }^{24}$

Median survival with spinal metastasis usually ranges from 3 to 18 months with RT. ${ }^{25-27}$ Median survival time in our group was extended to 13 months in the PVP combined with IMRT; there were no significant differences with other studies for patients with spinal metastatic patients in overall survival. It also showed that PVP combined with IMRT was only local and incomplete therapy for advanced patients with NSCLC, and systemic therapies, including chemotherapy, and molecular targeted therapy should be considered.

Of course, there are some limitations to our study. First, this was a retrospective, nonrandomized study. The sample size was small, and reasons for this include slow recruitment and patients' choice of other treatment regimes. Furthermore, there were a lack of references about randomized controlled trials for the assessment of VP as a therapeutic regime for lumbar scoliosis. Future extended studies with larger patient 
sample are necessary to support and prove these preliminary results. In conclusion, PVP combinations with IMRT could be a safe and effective procedure as a treatment for painful bone metastatic cancer.

\section{Disclosure}

The authors report no conflicts of interest in this work.

\section{References}

1. Heldmann U, Myschetzky PS, Thomsen HS. Frequency of unexpected multifocal metastasis in patients with acute spinal cord compression. Evaluation by low-field MR imaging in cancer patients. Acta Radiol. 1997;38(3):372-375.

2. Bohm P, Huber J. The surgical treatment of bony metastases of the spine and limbs. J Bone Joint Surg Br. 2002;84(4):521-529.

3. Masala S, Chiocchi M, Taglieri A, et al. Combined use of percutaneous cryoablation and vertebroplasty with $3 \mathrm{D}$ rotational angiograph in treatment of single vertebral metastasis: comparison with vertebroplasty. Neuroradiology. 2013;55(2):193-200.

4. Boschi V, Pogorelic Z, Gulan G, Perko Z, Grandic L, Radonic V. Management of cement vertebroplasty in the treatment of vertebral hemangioma. Scand J Surg. 2011;100(2):120-124.

5. Barragan-Campos HM, Vallee JN, Lo D, et al. Percutaneous vertebroplasty for spinal metastases: complications. Radiology. 2006;238(1): 354-362.

6. Masala S, Calabria E, Nezzo M, De Vivo D, Neroni L, Simonetti G. Clinical evaluation of percutaneous vertebroplasty in a patient with paraplegia and immobilization syndrome: a case report. Case Rep Radiol. 2013;2013:356109.

7. Filippiadis DK, Papagelopoulos P, Kitsou M, et al. Percutaneous vertebroplasty in adult degenerative scoliosis for spine support: study for pain evaluation and mobility improvement. Biomed Res Int. 2013; 2013:626502.

8. Sun Z, Zhao H, Yang H. Vertebral augmentation and radiation therapy: which should be given first to patients with malignant vertebral compression fractures? Pain Physician. 2011;14(6):569-570.

9. Sun ZY, Zhao H, Wu GZ, et al. Kyphoplasty for the treatment of vertebral compression fractures with anterior vertebral wall destruction: how can we do it better? Pain Physician. 2012;15(1):95-96.

10. Chen LH, Hsieh MK, Niu CC, Fu TS, Lai PL, Chen WJ. Percutaneous vertebroplasty for pathological vertebral compression fractures secondary to multiple myeloma. Arch Orthop Trauma Surg. 2012;132(6): 759-764.

11. Guo WH, Meng MB, You X, et al. CT-guided percutaneous vertebroplasty of the upper cervical spine via a translateral approach. Pain Physician. 2012;15(5):E733-E741.

12. Reisberg B, Finkel S, Overall J, et al. The Alzheimer's disease activities of daily living international scale (ADL-IS). Int Psychogeriatr. 2001; 13(2):163-181.
13. Witham TF, Khavkin YA, Gallia GL, Wolinsky JP, Gokaslan ZL. Surgery insight: current management of epidural spinal cord compression from metastatic spine disease. Nat Clin Pract Neurol. 2006;2(2): 87-94.

14. Brihaye J, Ectors P, Lemort M, Van Houtte P. The management of spinal epidural metastases. Adv Tech Stand Neurosurg. 1988;16:121-176.

15. Chow E, Zeng L, Salvo N, Dennis K, Tsao M, Lutz S. Update on the systematic review of palliative radiotherapy trials for bone metastases. Clin Oncol (R Coll Radiol). 2012;24(2):112-124.

16. Lim BS, Chang UK, Youn SM. Clinical outcomes after percutaneous vertebroplasty for pathologic compression fractures in osteolytic metastatic spinal disease. J Korean Neurosurg Soc. 2009;45(6):369-374.

17. Cortet B, Cotten A, Boutry N, et al. Percutaneous vertebroplasty in patients with osteolytic metastases or multiple myeloma. Rev Rhum Engl Ed. 1997;64(3):177-183.

18. Fourney DR, Schomer DF, Nader R, et al. Percutaneous vertebroplasty and kyphoplasty for painful vertebral body fractures in cancer patients. J Neurosurg. 2003;98(1 Suppl):21-30.

19. Pflugmacher R, Beth P, Schroeder RJ, Schaser KD, Melcher I. Balloon kyphoplasty for the treatment of pathological fractures in the thoracic and lumbar spine caused by metastasis: one-year follow-up. Acta Radiol. 2007;48(1):89-95

20. Kose KC, Cebesoy O, Akan B, Altinel L, Dincer D, Yazar T. Functional results of vertebral augmentation techniques in pathological vertebral fractures of myelomatous patients. J Natl Med Assoc. 2006;98(10): 1654-1658.

21. Masala S, Anselmetti GC, Marcia S, Massari F, Manca A, Simonetti G. Percutaneous vertebroplasty in multiple myeloma vertebral involvement. J Spinal Disord Tech. 2008;21(5):344-348.

22. Zhao H, Shi Q, Sun ZY, Gu QL, Ni L, Yang HL. The importance of percutaneous vertebroplasty and radiation therapy for pathological vertebral compression fractures secondary to multiple myeloma. Arch Orthop Trauma Surg. 2012;132(11):1669-1670.

23. Diamond TH, Hartwell T, Clarke W, Manoharan A. Percutaneous vertebroplasty for acute vertebral body fracture and deformity in multiple myeloma: a short report. Br J Haematol. 2004;124(4):485-487.

24. Lieberman I, Reinhardt MK. Vertebroplasty and kyphoplasty for osteolytic vertebral collapse. Clin Orthop Rrelat Res. 2003; (415 Suppl):S176-S186.

25. van der Linden YM, Dijkstra SP, Vonk EJ, Marijnen CA, Leer JW. Prediction of survival in patients with metastases in the spinal column: results based on a randomized trial of radiotherapy. Cancer. 2005;103(2): 320-328.

26. Gerszten PC, Mendel E, Yamada Y. Radiotherapy and radiosurgery for metastatic spine disease: what are the options, indications, and outcomes? Spine. 2009;34(22 Suppl):S78-S92.

27. Maranzano E, Bellavita R, Rossi R, et al. Short-course versus splitcourse radiotherapy in metastatic spinal cord compression: results of a phase III, randomized, multicenter trial. J Clin Oncol. 2005;23(15): 3358-3365.
OncoTargets and Therapy

\section{Publish your work in this journal}

OncoTargets and Therapy is an international, peer-reviewed, open access journal focusing on the pathological basis of all cancers, potential targets for therapy and treatment protocols employed to improve the management of cancer patients. The journal also focuses on the impact of management programs and new therapeutic agents and protocols on
Dovepress

patient perspectives such as quality of life, adherence and satisfaction. The manuscript management system is completely online and includes a very quick and fair peer-review system, which is all easy to use. Visit http://www.dovepress.com/testimonials.php to read real quotes from published authors. 